\title{
Teenage Marriage in Post Conflict Northern Uganda: A Case of Amuru District
}

\author{
Simple Ouma ${ }^{1, *}$, Kenneth Odong Obita ${ }^{2}$, Turyasima Mananura ${ }^{2}$, Acca Harriet Omara ${ }^{2}$, \\ Florence Nabbale ${ }^{2}$, Moses Toe Rama ${ }^{2}$, Caroline Cephas Adong ${ }^{2}$, Mpora Beatrice Odongkara ${ }^{2}$, \\ Emmanuel Igwaro Odongo-Aginya ${ }^{3}$, Silvia Awor ${ }^{4}$ \\ ${ }^{1}$ Department of Epidemiology and Biostatistics, Makerere University, Kampala, Uganda \\ ${ }^{2}$ Department of Pediatrics and Child Health, Gulu University, Gulu, Uganda \\ ${ }^{3}$ Department of Immunology and Microbiology, Gulu University, Gulu, Uganda \\ ${ }^{4}$ Department of Obstetrics and Gynaecology, Gulu University, Gulu, Uganda
}

Email address:

oumasimple@mail.com (S. Ouma)

${ }^{*}$ Corresponding author

\section{To cite this article:}

Simple Ouma, Kenneth Odong Obita, Turyasima Mananura, Acca Harriet Omara, Florence Nabbale, Moses Toe Rama, Caroline Cephas Adong, Mpora Beatrice Odongkara, Emmanuel Igwaro Odongo-Aginya, Silvia Awor. Teenage Marriage in Post Conflict Northern Uganda: A Case of Amuru District. Science Journal of Public Health. Vol. 6, No. 2, 2018, pp. 61-62. doi: 10.11648/j.sjph.20180602.15

Received: January 25, 2018; Accepted: February 16, 2018; Published: March 15, 2018

\begin{abstract}
Background: Teenage marriage eventually lead to teenage pregnancy with all it associated adverse consequences. Moreover, teenagers are less likely to utilize antenatal care and as well exhibit sub-optimal neonatal care compared to adult women. Thus, the need to report on teenage marriage in order to inform policy makers to provide necessary teenage sexual reproductive health services with relevant policies especially in post-conflict settings like Northern Uganda. Objectives: To describe prevalence and determinants of teenage marriage in post-conflict Northern Uganda. Methods: In this cross-sectional study, data was collected from 424 females of reproductive age using pre-tested semi-structured questionnaires. Univariate and bivariate analyses were carried out using SPSS 16.0. Results: Mean age of study participants was 27 years. Majority of participants $(79.0 \%)$ and their husbands $(67.2 \%)$ were peasant farmers. Majority of participants were married $(85.8 \%)$ with about one-fifth $(18.1 \%)$ of the participants pregnant at the time of interview. Among the married participants, majority of the participants $(65.1 \%)$ and their husbands $(64.2 \%)$ had only primary education. Majority $(86.3 \%)$ of the married women first got married as teenagers. Mean age at first marriage was 17 years. Women in this population generally got married at early ages. Women who got married at younger ages were lowly educated and generally never had formal paid employments. Likewise, women who got married at younger ages were generally married to lowly educated men with no formal employments. In contrast, women who married later in life had better education and married men with better education level and above all such couples tend to engage in formal paid employments. In addition, women who got married at older ages had less number of live births and desired to give birth to less children than women who got married at younger ages. Conclusions: Women in post-conflict Northern Uganda are experiencing high level of teenage marriage. This put them at risk of not attaining necessary education and employable skills hence poverty. This calls for targeted interventions from both government and development partners in order to reverse the current trend in teenage marriage due to inequality in formal education and other social amenities and thus save the girl child from poverty.
\end{abstract}

Keywords: Teenage Marriage, Age at First Marriage, Rural Women, Post Conflict Settings

\section{Background}

Two-year trend analysis of teenage pregnancy among women recruited at age between 16-19 years old showed that Uganda had a higher rate $(57 \%)$ of teenage pregnancy compared to Tanzania (56\%) and Kenya (47\%). In all three countries, teenage pregnancy rate was higher among rural than urban population more especially in Uganda [1]. Finland study also found teenage mothers being more prevalent in rural than urban settings [2]. Systematic analysis showed that 
few girls seek health care services yet its use is protective against teenage pregnancy. Moreover, beside structural and gender inequalities, low level of education, low socioeconomic status are associated with higher rate of teenage pregnancy [3-5]. Secondary education in both Uganda and Malawi and higher household economic index in Burkina Faso was found to reduce early teenage sexual debut and thus early marriage [6]. Report showed that three in every four teenagers are undecided about their intention to use family planning methods and only $5 \%$ of the teenagers were using contraceptives [7] even though teenage use of contraceptives greatly reduce teenage pregnancy [8, 9]. Low level of teenage use of contraceptives potentially put sexually active teenagers at high risk of pregnancy and eventual teenage marriage as it is a tradition in Acholi culture to marry off any young girl who gets pregnant. Moreover, adverse events during pregnancy and post-natal period is higher among rural women and women with low education level compared to women in urban settings and the highly educated women [10]. Adverse consequences associated with teenage pregnancy include major depressive disorder, which is more common among teenagers with less education [11]. Teenagers are also more likely not to utilize antenatal care compared to adult women $[3,4]$. This could lead to poor pregnancy outcomes like pre-eclampsia, stillbirth and birth weight $[3,5,8,12]$, as well as sub-optimal neonatal care [13] which put the life of both the baby and the mother at greater risk of pregnancy related morbidity and mortality. Moreover, beside lack of community support system, adolescent friendly services for teenagers and particularly for teenage mothers are lacking in Uganda [14, 15]. Worst still, early teenage pregnancy is associated with increased odd of acquiring HIV infection and gender based violence [16]. However, mentorship of young girls on issues of teenage pregnancy and marriage was found to be protective against teenage marriage [17]. Reported first birth among teenagers in Uganda was $72.1 \%$ in 2011 , which attributed to lower use of contraceptive among this age group [18]. In conflict setting, systemic analysis showed increase in teenage marriages in many countries [19].

\section{Methods}

\subsection{Study Area}

This study was conducted in Atiak Health Centre IV, Atiak Sub-County, Kilak County, Amuru district, Northern Uganda. Atiak is along Gulu-Juba road, approximately 74 kilometers by road, north of Gulu city, 406 kilometers north of Kampala capital city of Uganda, and roughly 50 kilometers south of the South Sudan border. Subsistence agriculture is the backbone of the district economy, employing $98 \%$ of the population. In 2010, estimated population of the district was 234,100. Atiak Health Centre is the only Health Centre in Amuru district with only one medical Officer, a district with no general hospital making Atiak Health Centre IV the highest referral health center. According to the 2012 state of population report, literacy rate in Northern Uganda was just at $64 \%$ (females, $52 \%$ compared to males, $77 \%$ ) well below the national level of $73 \%$.

\subsection{Data Collection}

This was a descriptive cross-sectional study where quantitative data was collected among 424 participants between 15-49 years of age. Eligible study participants selected from both inpatient and outpatient departments using simple random sampling and systematic random sampling respectively to fill semi-structured questionnaires.

\subsection{Ethical Clearance}

Ethical clearance was obtained from St. Mary's Hospital Lacor Institutional Review Board and approvals were obtained from Amuru District Health Officer and the InCharge of Atiak Health Centre IV. All respondents gave a written informed consent before being included in the study.

\subsection{Data Analysis}

Univariate and bivariate data analysis done using SPSS version 16.0 .

\section{Results}

Four hundred and twenty four (424) women of reproductive age participated in this study. Mean age of study participants was 27 (25-30) years. Majority of respondent attained primary education $(65.1 \%)$, with very few reached advance level of education (2.8\%). Likewise, majority of respondent's sexual partners had primary education (64.2\%), with very few reaching advance level of education (3.5\%). Most of the women were married (85.8\%) compared to only $11.3 \%$ who were not married. Majority of respondents $(79.0 \%)$ and their husbands $(67.2 \%)$ were peasant farmers with only about $5 \%$ of the both the women and their husbands being formally employed with either government or other formal paid employers. Nine out every ten of the ever-married respondents first got married as teenagers $(86.3 \%)$ with almost three out of every four $(72.9 \%)$ of the ever-married women getting married at age of (15-19) years of age and up to $13.4 \%$ getting married at $<15$ years of age. Almost one-fifth $(18.1 \%)$ of women in this population were pregnant at time of the study.

Bivariate analyses showed that there was no significant correlation between women's age at time of study $(\mathrm{P}=0.543)$ with their age at first marriage. In addition, there was no significant correlation between women's marital status $(\mathrm{P}=749)$ with their age at first marriage. Nevertheless, respondents' age at first marriage, showed positive significant correlation with respondents' education level ( $\mathrm{P}<0.001)$, level of education of sexual partners of respondents $(\mathrm{P}<0.001)$ and respondents' main occupation $(\mathrm{P}<0.001)$. However, respondents' age at first marriage showed significant negative correlations with both respondent's numbers of live birth $(\mathrm{P}<0.001)$ and respondents' desired numbers of biological 
children $(\mathrm{P}=0.015)$. Likewise, respondents age showed a significant negative correlation with respondents' level of education $(\mathrm{P}=0.000)$.

Table 1. Socio-demographic characteristics of study women of Amuru District, Northern Uganda.

\begin{tabular}{|c|c|c|}
\hline Characteristics & Frequency $(\mathbf{N})$ & Percentage $(\%)$ \\
\hline \multicolumn{3}{|l|}{ Age in completed years } \\
\hline $15-19$ & 40 & 9.6 \\
\hline $20-24$ & 97 & 23.2 \\
\hline $25-29$ & 92 & 22.0 \\
\hline $30-34$ & 105 & 25.1 \\
\hline $35-39$ & 43 & 10.3 \\
\hline $40-44$ & 31 & 7.4 \\
\hline $45-49$ & 10 & 2.4 \\
\hline \multicolumn{3}{|l|}{ Highest Level of Education } \\
\hline No formal education & 49 & 11.6 \\
\hline Primary level & 276 & 65.1 \\
\hline Ordinary level & 87 & 20.5 \\
\hline Advance level and above & 12 & 2.8 \\
\hline \multicolumn{3}{|c|}{ Highest Level of Education of Sexual Partner } \\
\hline No formal education & 31 & 7.3 \\
\hline Primary level & 272 & 64.2 \\
\hline Ordinary level & 57 & 13.4 \\
\hline Advance level and above & 15 & 3.5 \\
\hline Unknown & 49 & 11.6 \\
\hline \multicolumn{3}{|l|}{ Marital Status } \\
\hline Never Married & 47 & 11.3 \\
\hline Married & 357 & 85.8 \\
\hline Divorced & 9 & 2.2 \\
\hline Widowed & 3 & 0.7 \\
\hline \multicolumn{3}{|c|}{ Age at First Marriage in completed years } \\
\hline$<15$ & 48 & 13.4 \\
\hline $15-19$ & 261 & 72.9 \\
\hline $20-24$ & 45 & 12.6 \\
\hline $25-29$ & 4 & 1.1 \\
\hline \multicolumn{3}{|l|}{ Current reported Pregnancy Status } \\
\hline Pregnant & 76 & 18.1 \\
\hline Not Pregnant & 344 & 81.9 \\
\hline \multicolumn{3}{|l|}{ Main Occupation } \\
\hline Housewife & 14 & 3.3 \\
\hline Farming & 332 & 79.0 \\
\hline Personal business & 16 & 3.8 \\
\hline Employee in private organization & 10 & 2.4 \\
\hline Government employee & 8 & 1.9 \\
\hline Student & 40 & 9.5 \\
\hline \multicolumn{3}{|l|}{ Main Occupation of Sexual partner } \\
\hline Farming & 250 & 67.2 \\
\hline Personal business & 96 & 25.8 \\
\hline Employee in private organization & 10 & 2.7 \\
\hline Government employee & 9 & 2.4 \\
\hline Student & 6 & 1.6 \\
\hline Others & 1 & 0.3 \\
\hline
\end{tabular}

\section{Discussion}

Majority of ever-married respondents (86.3\%) first got married as teenagers mostly at the age between $15-19$ years of age $(72.9 \%)$. This finding is in agreement with other previous reports showing that first birth among teenage women in Uganda was $72.1 \%$ in 2011 [18]. In the neighboring district of Gulu, among rural women in Awach, median age at first marriage was also 17 years. Median age at first sexual intercourse among same population was 16 years but more than $50 \%$ of the teenagers' initial sexual debuts were nonconsensual [20]. However, another study in Gulu district that recruited both rural and urban women showed mean age at first marriage to be 17.9 years among female compared to 23.2 among their male counterpart [21]. In Kampala, the capital city of Uganda, the mean age of sexual debut among female was also 16 years but most of the early sexual debut $(80.6 \%)$ was consensual [22]. Nonconsensual sexual intercourse often means having unprotected sex with increased risk of unwanted pregnancy. This eventually results into forced teenage marriage perpetrated by the girl's parents if they learn of the sexual contact or if the girl becomes pregnant. In this study, respondents' age showed a significant negative correlation with respondents' level of education, implying that younger generation achieved higher level of education than the older generation. In addition, there was no significant change in teenage marriage among the different age groups of the study participants. Therefore, the relative improvement in women's education level at population level across the different age groups did not significantly reduce teenage marriages. The above finding is in contrast with an Ethiopian study showing that mean age at first marriage increased from 17 to 18 years between 2005 and 2011 in parallel with increase in level of education [23].

However, at individual level, age at first marriage was positively correlated to highest level of education of these rural women and their husbands $(\mathrm{P}<0.001)$ respectively. This shows that women who first got married at older ages were more educated than those who first got married at younger ages. Likewise, husbands of women who first got married at older ages were more educated in comparison to husbands of the women who first got married at younger ages. The finding is in agreement with previous report showing that secondary education in both Uganda and Malawi reduces early teenage sexual debut and thus marriage [6]. Education level of these rural women is positively correlated to education level of their sexual partners $(\mathrm{P}<0.001)$. Majority of respondent attained primary education $(65.1 \%)$, with very few reaching advance level of education (2.8\%). Majority of respondent's sexual partners had primary education (64.2\%), with very few reaching advance level of education (3.5\%). The above findings are in agreement with findings in South Asia [3] and Nigeria [10], where early teenage marriage among girls and teenage pregnancy were also associated with low education level. This underscore the usefulness to keep girls in school as a measure to reduce teenage marriage. Moreover, majority of respondents $(79.0 \%)$ and their husbands $(67.2 \%)$ were peasant farmers with only about $5 \%$ of the either the women or their husbands being formally employed with either government or other formal paid employees. Being peasant a farmer and marrying another peasant farmer at the same time is indirect indicator of low socio-economic status among this community. Therefore, there is a possibility of a vicious cycle of low socio-economic status leading to low education level leading to teenage marriage and vice versa. Unless the cycle is broken, there is a possibility of continuation of the current trend of teenage marriage. 


\section{Conclusions and Recommendations}

Post-conflict Northern Uganda is still experiencing unacceptably high level of teenage marriage, which requires targeted interventions from both the government and development partners to reverse this alarming trend. Moreover, women with low education are more likely to marry men low education at a much younger age putting herself and children to vicious circle of poverty.

Therefore, more studies are needed to determine the level of formal education that can be a sufficient intervention to reduce teenage marriage in post-conflict settings like Northern Uganda. Likewise, young girls should be economically empowered so that they do not get distracted to marry off due to socio-economic challenges they face in school under severe financial stress. Finally, we recommend further in-depth studies into this phenomenon of teenage marriages in post-conflict northern Uganda.

\section{Acknowledgements}

This study was a MESAU-MEPI Supported Undergraduate Mentored Research, Awarded through Award Number 1r24tw008886 (MESAU-MEPI Programmatic Award) from the Fogarty International Center 2014. The authors appreciate all respondents, the In-charge and Staffs of Atiak HC IV, office of the Amuru District Health Officer, for their cooperation during data collection, Mr. Luryama-Moi Kenneth and Mr. Onen Yagos of Faculty of Medicine, Gulu University, for their support.

\section{Funding}

This study was made possible through a MESAU-MEPI Supported Undergraduate Mentored Research, Awarded through Award Number 1r24tw008886 (MESAU-MEPI Programmatic Award) from the Fogarty International Center 2014.

\section{Conflict of Interest}

None.

\section{References}

[1] Neal SE, Chandra-mouli V and Chou D. Adolescent first births in East Africa: disaggregating characteristics, trends and determinants. Reprod Health. 2015; 12 (13):1-13.

[2] Leppälahti S, Gissler M, Mentula M and Heikinheimo O. Is teenage pregnancy an obstetric risk in a welfare society? A population-based study in Finland, from 2006 to 2011. BMJ. $2013 ; 3$

[3] Raj AD, Rabi B, Amudha P, Assistant P, Group E, Health P, et al. Factors associated with teenage pregnancy in South Asia: a systematic review. Heal Sci J. 2010; 4 (1):3-14.
[4] Taffa N and Obare F. Pregnancy and child health outcomes among adolescents in Ethiopia. EthiopJHealth Dev. 2004; 18 (2).

[5] Garba I, Adewale TM, Ayyuba R and Abubakar IS. Obstetric outcome of teenage pregnancy at Aminu Kano Teaching Hospital : A 3 - year review. J Med Trop. 2016; 18 (1):43-6.

[6] Stephenson R, Simon C and Finneran C. Community Factors Shaping Early Age at First Sex among Adolescents in Burkina Faso,. J Heal Popul Nutr. 2014; 32 (2):161-75.

[7] Ouma S, Turyasima M, Acca H, Nabbale F, Obita KO, Rama $\mathrm{M}$, et al. Obstacles to family planning use among rural women in atiak Health Center IV, Amuru district, Northern Uganda. East Africa Medica Journal. 2015; 92 (8):394-400.

[8] Pietri G and Yu J. Association between long-acting reversible contraceptive use, teenage pregnancy, and abortion rates in England. Int J Womens Health. 2014; 6:961-74.

[9] Mcnicholas C, Mullersman J, Buckel CM, Zhao Q and Peipert JF. Provision of No-Cost, Long-Acting Contraception and Teenage Pregnancy. N Engl J Med. 2014; 371 (14).

[10] Fagbamigbe AF and Idemudia ES. Survival analysis and prognostic factors of timing of first childbirth among women in Nigeria. BMC Pregnancy Childbirth. 2016; 16 (102):1-12.

[11] Monteiro F, Pinheiro RT, Silva RA, Quevedo LDÁ, Dias L, Souza DM, et al. Major depressive disorder during teenage pregnancy: socio-demographic, obstetric and psychosocial correlates. Rev Bras Psiquiatr Psychiatry. 2013; 51-6.

[12] Namagembe I, Kasangaki A and Cecily B. Prevalence and Factors Associated with Low Birth Weight among Teenage Mothers in New Mulago Hospital: A Cross Sectional study. J Heal Sci. 2016; 4:192-9.

[13] Kabwijamu L, Waiswa P, Kawooya V, Nalwadda CK and Okuga M, Nabiwemba EL. Newborn Care Practices among Adolescent Mothers in Hoima District, Western Uganda. PLoS One. 2016; 11 (11):1-12.

[14] Rukundo GZ, Abaasa C, Natukunda PB, Ashabahebwa BH and Allain D. Antenatal services for pregnant teenagers in Mbarara Municipality, Southwestern Uganda : health workers and community leaders' views. BMC Pregnancy Childbirth. $2015 ; 15$ (351):1-5.

[15] Atuyambe LM, Kibira SPS, Bukenya J, Muhumuza C, Apolot $\mathrm{RR}$ and Mulogo E. Understanding sexual and reproductive health needs of adolescents: evidence from a formative evaluation in Wakiso district, Uganda. Reprod Health. 2015; $12(35): 1-10$.

[16] Christofides NJ, Jewkes RK, Dunkle KL, Nduna M, Shai NJ and Sterk C. Early adolescent pregnancy increases risk of incident HIV infection in the Eastern Cape, South Africa: a longitudinal study. J Int AIDS Soc. 2014; 17:1-7.

[17] Mezey G, Meyer D, Robinson F, Bonell C, Campbell R, Gillard S, et al. Health technology assessment. Health Technol Assess (Rockv). 2015; 19 (85).

[18] Kabagenyi A, Habaasa G and Rutaremwa G. Europe PMC Funders Group Low Contraceptive Use among Young Females in Uganda : Does Birth History and Age at Birth have an Influence? Analysis of 2011 Demographic and Health Survey. J Contracept Stud. 2017; 1 (1):1-12. 
[19] Neal S, Stone N and Ingham R. The impact of armed conflict on adolescent transitions : a systematic review of quantitative research on age of sexual debut, first marriage and first birth in young women under the age of 20 years. BMC Public Health. 2016; 16 (225):1-11.

[20] Patel S, Schechter MT, Sewankambo NK, Atim S, Kiwanuka $\mathrm{N}$ and Spittal PM. Lost in Transition: HIV Prevalence and Correlates of Infection among Young People Living in PostEmergency Phase Transit Camps in Gulu District, Northern Uganda. PLoS One. 2014; 9 (2):14-8.

[21] Mwaka AD, Orach CG, Were EM, Lyratzopoulos G, Wabinga $\mathrm{H}$ and Roland $\mathrm{M}$. Awareness of cervical cancer risk factors and symptoms : cross-sectional community survey in. Heal Expect. 2015; 19:854-67.

[22] Renzaho AMN, Kamara JK, Georgeou N and Kamanga G. Sexual, Reproductive Health Needs, and Rights of Young People in Slum Areas of Kampala, Uganda: A Cross Sectional Study. PLoS One. 2017; 12 (1):1-21.

[23] Reda AA and Lindstrom D. Recent trends in the timing of first sex and marriage among young women in Ethiopia. Etude Popul Afr. 2014; 28 (2):1157-70. 